\title{
Using the Markov Model to simulate and predict the land use change in1992-2030 in the Yangtze River Economic Belt, China
}

\author{
Guangyuan Niu ${ }^{1}$, Qingxiang Zhang ${ }^{1}$, Huan Liu ${ }^{1}$, Yuxi Yang ${ }^{1}$, Hong Yao ${ }^{1}$, and Tongzhu \\ Zhang $^{1}$ \\ ${ }^{1}$ Nantong University
}

July 29, 2020

\begin{abstract}
The land use changes directly reflected the economic and environmental development status of the region in a certain period, and the indicator can be applied in analyzing the role and economic benefits of various administrative departments. The Yangtze River Economic Belt, China is one of the "three major strategic development regions at the national level" implemented by the nation. The Markov prediction model was introduced to simulate the land use changes in the region and the average accuracy of the simulation was $99.54 \%$. In the simulation the four regional development stages from 1992 to 2018 were identified in the model: primitive development, rapid urban expansion priority, ecological restoration priority and equilibrium on urban expansion and ecological restoration. Various scenarios with different transition probability matrix were characterized on diverse socio-economic conditions. The mean values were introduced in the prediction model. The land use changes in the Yangtze River Economic Belt in 2020-2030 were predicted and the characteristics of the changes in various scenarios were analyzed so as to provide scientific suggestions for decision makers on the sustainable utilization of the land in the densely populated and ecologically sensitive area.
\end{abstract}

Using the Markov Model to simulate and predict the land use change in1992-2030 in the Yangtze River Economic Belt, China Guangyuan Niu ${ }^{1,2}$, Qingxiang Zhang ${ }^{1,2}{ }^{1}$ Huan $\mathrm{Liu}^{1,2}$, Yuxi Yang ${ }^{1}$, Hong Yao ${ }^{1,2^{*}}$, Tongzhu Zhang $^{3^{*}}$ 1: School of Geography, Nantong University, Nantong, 226019, China 2: Jiangsu Yangtze River Economic Belt Research Institute, Nantong, 226019, China 3:School of Liberal Arts, Nantong University, Nantong, 226019, China *Corresponding author Hong Yao and Tongzhu Zhang will handle the correspondence at all stages of refereeing and publication, also post-publication. Phone: +86 13515203950; fax: +86 513 85015880; E-mail: yaohong@ntu.edu.cn; zhangtongzhu@ntu.edu.cn Guangyuan Niu: 771435713@qq.com Qingxiang Zhang: 1534527000@qq.com Huan Liu: 1049804901@qq.com Yuxi Yang: 552437383@qq.com

\section{Author Contributions:}

Hong Yao conceived and designed the study; Guangyuan Niu, Qingxiang Zhang and Huan Liu performed the simulation; Guangyuan Niu and Tongzhu Zhang wrote the paper; Qingxiang Zhang, Huan Liu, Yuxi Yang collected the data and critically reviewed the manuscript and added helpful explanations. All authors approved the final version of the manuscript. Conflicts of Interest: The authors declare no conflict of interest.

\section{ACKNOWLEDGEMENT}

This work was sponsored by the National Natural Science Foundation of China (41501601) and the Natural Science and Technology Project of Nantong(MS12018035). No conflict of interest exits in the submission of 
this manuscript, and the manuscript is approved by all authors for publication.

\section{Data Availability Statement}

The data that support the findings of this study are available on request from the corresponding author. The data are not publicly available due to privacy restrictions. Abstract: The land use changes directly reflected the economic and environmental development status of the region in a certain period, and the indicator can be applied in analyzing the role and economic benefits of various administrative departments. The Yangtze River Economic Belt, China is one of the "three major strategic development regions at the national level" implemented by the nation. The Markov prediction model was introduced to simulate the land use changes in the region and the average accuracy of the simulation was $99.54 \%$. In the simulation the four regional development stages from 1992 to 2018 were identified in the model: primitive development, rapid urban expansion priority, ecological restoration priority and equilibrium on urban expansion and ecological restoration. Various scenarios with different transition probability matrix were characterized on diverse socio-economic conditions. The mean values were introduced in the prediction model. The land use changes in the Yangtze River Economic Belt in 2020-2030 were predicted and the characteristics of the changes in various scenarios were analyzed so as to provide scientific suggestions for decision makers on the sustainable utilization of the land in the densely populated and ecologically sensitive area. Keywords: land use change; the Markov Model; the Yangtze River Economic Belt

\section{Introduction}

The land use changes directly reflected the economic and environmental development status of the region in a certain period, and the indicator can be applied in analyzing the role and economic benefits of various administrative departments(Gerard et al., 2010; Najmuddin, Deng, \& Jia, 2017; Parcerisas et al., 2012).In recent years, the Yangtze River Economic Belt has become more and more prominent in economic growth and been heatedly discussed by the researchers and the governments at all levels(Bai, Shi, \& Liu, 2014; Ma et al., 2014). It has become a region with the strongest comprehensive strength, the greatest strategic support, the unique advantages and the huge development potential in the nation, according to this characterizing and forecasting the land use change of the Yangtze River Economic Belt in recent years is one vital topic for its subsequent sustainability development. The quantitative analysis of the land use changes was one of the main topics discussed. The GIS technology and the remote sensing data have been regularly applied in the areas and cities with rapid urbanization process to analyze regional land use changes(Islam, Miah, \& Inoue, 2016; Parcerisas, et al., 2012). The changes of the land coverage, land use structure were measured as the indicators urban sustainable development(Fischer \& Lindenmayer, 2006; Li et al., 2015). The impact of the land use change on the urban microclimate was verified from an ecological perspective(Eitelberg, van Vliet, Doelrnan, Stehfest, \& Verburg, 2016; Prestele et al., 2017; Schwartz et al., 2015). The mathematics models have been commonly applied simulating and predicting the land use changes (Bohnes, Gregg, \& Laurent, 2017; Brunner, Huber, \& Gret-Regamey, 2017; Ottinger, Clauss, \& Kuenzer, 2016).Agent-based land-use models have been widely used in assessing regional land use changes(Becu, Perez, Walker, Barreteau, \& Le Page, 2003; Brown, Page, Riolo, \& Rand, 2004; Matthews, Gilbert, Roach, Polhill, \& Gotts, 2007). Google earth engine was used in mapping the changes of national-scale aquaculture ponds(Duan et al., 2020; X. X. Wang et al., 2020). Ecological interference evaluation method was introduced in the dynamic evaluation of the land use changes in rapid urbanization of coastal zones(Yi, Qian, Kobuliev, Han, \& Li, 2020; Zhang et al., 2019). The development policy was assessed by simulating the sustainable land-use scenario(Fan, Wang, Wang, Chen, \& Zhou, 2018; Li, et al., 2015). The spatial structures of major function zoning in China were explored using the spatial modeling and landscape metrics methods(Fan et al., 2019; Y. F. Wang \& Fan, 2020). Land-use and sustainability for Australia to 2050 were predicted under intersecting global change and domestic policy scenarios using the Land-Use Trade-Offs (LUTO) model(Bryan et al., 2016; Goldstein et al., 
2012). State-and-transition simulation models were proposed for forecasting landscape change(Daniel, Frid, Sleeter, \& Fortin, 2016; Krasa, Dostal, Vrana, \& Plocek, 2010). The Yangtze River Economic Belt is one of the "three major strategic development regions at the national level" implemented by the nation. The land use change in the region might be typical, being the pioneering demonstration of the regional sustainability development and the construction of ecological civilization in the whole nation. The assessment of the land use changes in the area including the simulation and prediction, and the latter is an urgent work to be done. Thus the aims of this study were: (1) to introduce one mathematical model to simulate the land use changes in the region and assess the accuracy of the model in the simulation; (2) to assess the trend of the land use changes in 1992-2018 and describe the characteristics of the changes in the region; (3) to predict the land use change in 2020-2030 in several regional development scenarios and evaluate the impact of various scenarios on the changing so as to provide scientific suggestions for decision makers on the sustainable utilization of the land in the densely populated and ecologically sensitive area.

\section{Materials and methods}

\subsection{Study area}

The Yangtze River Economic Belt, China covers eleven provinces including Shanghai, Jiangsu, Zhejiang, Anhui, Jiangxi, Hubei, Hunan, Chongqing, Sichuan, Yunnan, and Guizhou. All the provinces are on the two sides of the Yangtze River(Figure 1).

Figure 1 the sketch map of the Yangtze River Economic Belt, China

The region has an area of approximately 2,052,300 square kilometers, accounting for $21.4 \%$ of the total area of the nation. Both the population and the gross domestic product in 2019 exceeded $40 \%$ of the whole nation. The Yangtze River Economic Belt spans from the eastern China, through the central China to the western China. It is one of the "three major strategic development regions at the national level" implemented by the nation. The land use change in the region might be typical, being the pioneering demonstration of the regional sustainability development and the construction of ecological civilization in the whole nation.

\subsection{Data Sources}

The images applied in the simulation and prediction of the land use changewas downloaded from the official website (https://maps.elie.ucl.ac.be/CCI/viewer/)of the global land use cover images provided by the European Space Agency (abbreviated as ESA). The resolution of the images was 300 meters. The data analyzed in the study covers the images in 1992, 1994, 1996, 1998, 2000, 2002, 2004, 2006, 2008, 2010, 2012, 2014, 2016, 2018 and totally 14 periods of land use data, spanning 27 years, were introduced into the model in the simulation and prediction.

\subsection{Data processing}

The original images obtained were all in NETCDF format. In order to facilitate the subsequent statistics and calculation, the NETCDF format data were converted into the GEOTIFF ones. The GDALWARP tool in GDAL was applied to process the source data. In the processing, the land use cover classifications in the source data were extracted and the projections of the images were all defined as the WGS84 coordinate system. All the images were cropped according to the scope of the Yangtze River Economic Belt. In order to intuitively display the land use structure, the classifications of the original data were simplified and the reclassification tool was applied according to the principles listed in Table 1. 


\subsection{The prediction model introduced}

\subsubsection{The Markov prediction method}

The Markov prediction method was used to simulate and predict the land use change in the Yangtze River Economic Belt, which was a methodology to describe the probability of the occurrence of an event based on the Markov chain. It predicted the status in the future time (or period) according to the current status of the event. The Markov prediction is an effective method in presenting the geographic time, being one important method applied in geographic science. In the Markov prediction, state is an important term. The so-called state refers to a certain result that occurs at a certain time or period at a certain time. For example, the land cover category at a place was cropland in the certain years. The development of an event from one state to another is called state transition. For example, the process of cropland turning into urban areas was a state transition process. In the development of an event, if each state transition is related to the state at the previous moment, but not to the past state, or the state transition process is not aftereffect, this state transition process is called the Markov process. The state transition in the development process of many geographic events is ineffectual, as is the change in land use. In the process of event development and change, the possibility of starting from a certain state and transitioning to another state at the next moment was called the state transition probability (abbreviated as $P$ ).According to the definition of conditional probability, the state transition probability $P\left(E_{i}-E_{j}\right)$ from the state $E_{i}$ to the state $E_{j}$ was the conditional probability $P\left(E_{i} / E_{j}\right)$. Thus, $P_{i j}$ was defined as: $P\left(E_{i}-E_{j}\right)=P\left(E_{i} / E_{j}\right)=P_{i j}$ If the development process of an event has $\mathrm{n}$ kinds of possible states, namely $E_{1}, E_{2}, \ldots, E_{\mathrm{n}}$ and $P_{i j}$ is the state transition probability from the state $E_{i}$ to the state $E_{j}$, the matrix $P$ is called the state transition probability matrix. In the matrix, the $P_{i j}$ values conforms to the following condition: In the Markov prediction, the calculation of the state probability was the most vital step. $\pi_{\vartheta}(k)$ represented the probability being in the state $E_{j}$ at the $k$-th period after the $k$-state transitions and the initial state $(k=0)$ was known. The state $E_{i}(i=1,2, \ldots, n)$ could be reached after the $(k-1)$-state transitions and the state $E_{j}$ was defined as the state in the $k$-state transitions. According to the inefficiency of the Markov process and the Bayes conditional probability formula, the relationship could be presented as: If the line vector $\pi(k)=\left(\pi_{1}(k), \pi_{2}(k), \ldots, \pi_{\nu}(k)\right)$, the above formula could be simplified to be: In which, $\pi(0)=\left(\pi_{1}(0), \pi_{2}(0), \ldots, \pi_{\nu}(0)\right)$ was the initial vector.

\subsubsection{Establishment of the state transition probability matrix}

The land cover state transition probability matrix was counted according to the data on the land use classification. The data in 1992 were multiplied by 10 for distinguishing the difference using the the grid calculator tool and the data for the previous two years were added. The tens digit of the values indicated the land use in 1992, being the initial value of the model, and the single digit indicated the land use changes in the subsequent years. All the attributes of the land use data could be exported from the model and analyzed. The areas occupied by the classes with the same ten-digit number of the category code were added to count the total area of a certain land use type at the initial moment. The transfer probabilities of the land cover state were the ratios of the various types of area, which were summed according to the transfer proportions of one land cover type to the other one.The calculation formula was: In which $S_{i j}$ was the area of the $i$-th land cover type to the $j$-th type in a certain period, $S_{i 0}$ was the area of the $i$-th land cover type at the initial moment in the simulation model, and $P_{i j}$ was the transition probability of the land cover state. Thus, the transfer probabilities of the land cover between different types could be calculated respectively and the transfer probability matrix of the land cover state were obtained in each intervals of the year. Totally 13 phases of land cover state transition probability matrix could be exported from the model(1992-1994, 1994-1996, 1996-1998, 1998-2000, 2000-2002, 2002-2004, 2004-2006, 2006-2008, 2008-2010, 2010-2012, 2012-2014, 2014-2016, 2016-2018).

\subsubsection{Test on the accuracy of the model}

The annual average transfer matrix of the 13-periods and the land cover state transfer probability matrix in 2018 were the initial state transfer probability matrix in the prediction model. The land use data in 1992 
was used as the initial vector $\pi(0)$, and $k$ was assigned in the program to simulate the land use changes from 1992 to 2018. The actual and simulated land use values in 2018 were listed in Table 2 and all the relative errors were also presented in the table. The average accuracy of the simulation was $99.54 \%$. The high accuracy rate indicated that the model introduced could be applied in simulating and predicting the land use changes in the Yangtze River Economic Zone.

\section{Results and discussion}

\subsection{Regional development scenarios in 1992-2018}

In the simulation of the land use changes in the Yangtze River Economic Zone, the following four regional development stages from 1992 to 2018 could be identified in the model and various scenarios with different transition probability matrix were characterized on diverse socio-economic conditions.

\subsubsection{Scenario1: primitive development stage}

In 1992-1998, the land and resources department had not been established and the land use had not been comprehensively managed, so we call it the primitive development stage. In this period the land use management was relatively loose and the natural state of the ecology was maintained. The average values of the transfer probability matrix on the land use from 1992 to 1998 were listed in Table 3 as the characteristics in the primitive development scenario. The main transfer directions of various types of land were the cultivated land, forested land and construction land. The cultivated land was mainly transferred from the forest land, shrub forest, grassland and water surface(Table 3). This indicated that under primitive development, the cultivated land mainly came from the deforestation, land reclamation and lake/sea reclamation. Forest land was transferred from the shrubs, the grasslands, a small part of cultivated land and wetland. Since there were no control measures for the ecology in the scenario of the natural development, the transfer of the forest land mainly came from the natural growth of the vegetation. Construction land was mainly transferred from the agricultural land, shrubbery, grassland, wetland, bare land and water surface, etc. This meant that in the natural development situation, people's demand for construction land was not high, and only stayed on the basic demand. In addition, the land such as the water surface had also undergone insignificant changes due to natural causes.

\subsubsection{Scenario2: rapid urban expansion priority}

From 1998 to 2008, the urban construction and vigorously developing productivity were emphasized in China and it was the fastest decade contributing to the nation's economic growth. We call this period the rapid urban expansion priority period. During this period in order to maintain a high rate of economic development, many short-term effective economic stimulus policies including rapid urban expansion have been promulgated, while the economic and social sustainability, ecosystem health and the balance of land use were ignored. The mean values of the transfer probability matrix on the land use in the ten years was listed in Table4 charactering the land cover in the rapid development scenarios. In the land cover transfer probability matrix, the transfer-in and transfer-out proportions of various land use types have increased significantly compared with the primitive development stage. The cultivated land was still mainly transferred from the forest land, shrubbery, grassland and water surface. However, the proportions of the transferred land were obviously intensified compared those in the scenario 1 . The proportions of the shrubbery and grassland conversion even exceeded those of the scenario 1 in some periods. The indicators showed that the economic development promoted the development of agriculture and accelerated the expansion of cultivated land in the ten years. Due to the demand for the timber in the economic development, a large number of shrubs and some cultivated land were converted into the forest land. In the stage, the construction land has rapidly expanded for the massive demand of the secondary and tertiary industries, occupying the agricultural land, 
shrubs, grasslands and wetlands. Due to the land reclamation, the rate of water surface being converted to the cultivated land, wetland and grassland increased significantly(Table 4).

\subsubsection{Scenario3: ecological restoration priority}

In order to limit the problems of ecological imbalance, resource mismatch and dysfunction caused by excessive economic development, the administrative department strengthened the supervision of various indicators on regional land use. From 2008 to 2014,the sustainable development strategies were implemented in the whole nation and the concept of the scientific development was required. The average values of the transfer matrix on the land use in 2008-2014 were presented in table 5. In the stage of the ecological restoration priority, the ratio of various lands transferred to the cultivated one has been significantly reduced(Table 5). Especially such ratio has been effectively controlled as of the forest land, shrub land, grassland, and surface water transferred to the cultivated land. However, in the stage the economic growth was still fast and required a lot of areas of the construction land. The conversion rate of the construction land from the cultivated land, grassland, wetland and bare land was still large(Table5). Due to the protection of the aquatic ecology, part of the wetlands turned into the surface water.

\subsubsection{Scenario4: equilibrium on urban expansion and ecological restoration}

From 2014 to 2018, the economic growth rate shifted from high-speed growth to medium-speed growth and the driving force for economic development has shifted from investment-driven and urban expansion to innovation-driven and service-driven. The average values of the transfer matrix of the land use changes from 2014 to 2018 were described in table 6. Compared with the other three scenarios, the most obvious feature in the stage of the Equilibrium on urban expansion and ecological restoration was that the ratio of other land use types transferred to the cultivated land was significantly reduced. In this stage, the cultivated land was mainly transferred from the bare land and the ratio of the arable land being transferred to the construction land decreased. The increasing of the forest land and the shrubs was both not obvious. The grassland mainly transferred to the construction land and woodland, which indicated that the strict ecological protection measures adopted came into effect.

\subsection{The prediction of the land use changes in 2020-2030}

The land use data in 2018 was input in the model as the initial vector $(\pi(0))$ and the transition probability matrices of the above four stages were respectively brought into the Markov model as the four development scenarios in the prediction of the land use of the Yangtze River Economic Belt. The prediction step was set as 2 years and corresponding the step size $k$ was $1,2,3,4,5$, and 6 respectively. The predicted values of the land usein 2020, 2022, 2024, 2026, 2028, and 2030 were obtained from the prediction model.

\subsubsection{The prediction in the scenario1}

The land use prediction from 2020 to 2030 in the scenario1 was listed in the table7. Under the primitive development situation, the proportion of the cultivated land, wetland, construction land and water surface gradually increased, and the proportion of the forested land, shrubland and grassland gradually decreased. There was no significant change in the areas of the bare land, perennial snow and ice land. Among the nine land use types, the cultivated land and construction land increased the fastest. In the primitive development scenario, the expansion rate of the cultivated land was obvious due to the lack of economic incentives and ecological protection. Compared with the other three scenarios, the growth rate of the cultivated land was the fastest in the scenario. Because of the same reason, the growth rate of construction land is the slowest among the four scenarios. The decrease rates of the woodland and grassland were both the fast among the four scenarios. In the scenario of primitive development, the social, economic and ecological conditions maintained a natural state of development. The growth of the construction land was predicted to be in the slow level, which might be not conducive to the economic growth of the region. Besides, the expansion of the 
cultivated land might cause great damage to the natural ecology, which was not conducive to the sustainable development of the Yangtze River Economic Belt.

\subsubsection{The prediction in thescenario2}

In the development scenario of rapid urban expansion priority, the cultivated land, wetland and construction land could increase year by year and the forest land, shrub land, grassland and water surface would decrease year by year(Table 8) In the prediction, due to the accelerated expansion of the construction land, the growth rate of the cultivated land was significantly reduced compared with the primitive development scenario and the growth rate of the construction land was faster. Besides, the wetlands have also experienced rapid growth for the decreasing of the area of the surface water. It can be seen from the above changes that due to the rapid economic development, the changes in the industrial composition were reflected by the land cover prediction of the Yangtze River Economic Zone and gradually tilted to the secondary and tertiary industries. The proportion of the woodland, shrubland, grassland, and water surface land declined. In the scenario, the rapid urban expansion might lead to the expansion of the construction land and cultivated land and the expansion caused the rapid decreasing of the proportion of the woodland, grassland and shrubland. Besides, the urban expansion might bring about the reducing of the area of the surface water and increasing the proportion of the wetlands.

\subsubsection{The prediction in thescenario3}

In the scenario of the ecological restoration priority, the arable land, woodland, shrub forest, grassland, and water surface decreased year by year, and the wetland and construction land increased. In the scenario, the change characteristics of the cultivated land were different from the previous two scenarios (Table 9). The ecological protection policies restricted the expansion of cultivated land and the area of the cultivated land decreased. However, there was still a great demand for the construction land and the expansion of the construction land required the reduction of the cultivated land to achieve the balance between the lands' occupation and compensation. The expansion rate of the construction land increased year by year and the rate was the highest among the four scenarios. In the scenario, due to the strategy of the ecological restoration priority, the woodlands, shrubs, grasslands, water surfaces and wetlands would be effectively protected and the rapid expansion of the cultivated land could be controlled. The construction land would still expand rapidly and directly lead to the reduction of the cultivated land.

\subsubsection{The prediction in the scenario4}

In the scenario of the equilibrium on urban expansion and ecological restoration, the ratio of the cultivated land, shrubbery, and grassland decreased and the forest land, construction land, and water area gradually increased(Table 10). The reduction rate of the arable land was the fastest of the four scenarios. The transfer probability matrix listed in section 3.1.4 presented that the cultivated land has mainly transferred into the forest land and the construction land. This might be caused by the policy of turning the farmland to the forest in the whole nation. In the scenario prediction, the change ratios of the forest land and the shrubbery were both low, which was one feature distinguished from the other three scenarios prediction and showed the protection of the ecological environment in the Yangtze River Economic Belt came into effect. The growth rate of the proportion of the construction land would reduce and the slowdown in the economic growth rate was reflected in the changes of the land use. In the scenario, the equilibrium on urban expansion and ecological restoration would be emphasized in the Yangtze River Economic Belt, which would directly lead to the improvement of the whole ecological environment. The proportion of the forest land could increase and that of the shrubbery and grassland would be controlled. The growth rate of the construction land would reduce. However, the rapid decline in the proportion of the agricultural land was worth noting, which was directly related to the food security in the nation with large population. And some protective measures should be implemented for the increasing of the agricultural land. 


\section{Conclusion}

Based on the Markov prediction model, the land use changes in the Yangtze River Economic Belt from 1992 to 2018 were simulated and those in 2020-2030 were predicted. The average accuracy of the simulation was 99.54\%. The high accuracy rate indicated that the Markov model introduced could be applied in simulating and predicting the land use changes in the Yangtze River Economic Zone, one of the "three major strategic development regions at the national level" implemented by the nation. In the simulation of the land use changes in the study area, the four regional development stages from 1992 to 2018 could be identified in the model: primitive development stage, rapid urban expansion priority, ecological restoration priority and equilibrium on urban expansion and ecological restoration. Various scenarios with different transition probability matrix were characterized on diverse socio-economic conditions. The four development scenarios were applied in the prediction of the land use and the mean values of the transfer probability matrix in each stage were introduced in the prediction model. The land use changes in the Yangtze River Economic Belt in 2020, 2022, 2024, 2026, 2028, and 2030 were described and the characteristics of the changes in various scenarios were analyzed so as to provide scientific suggestions for decision makers on the sustainable utilization of the land in the densely populated and ecologically sensitive area.

\section{References:}

Bai, X. M., Shi, P. J., \& Liu, Y. S. (2014). Realizing China's urban dream. Nature, 509 (7499), 158-160. doi: $10.1038 / 509158 \mathrm{a}$

Becu, N., Perez, P., Walker, A., Barreteau, O., \& Le Page, C. (2003). Agent based simulation of a small catchment water management in northern Thailand description of the CATCHSCAPE model. Ecological Modelling, 170 (2-3), 319-331. doi: 10.1016/s0304-3800(03)00236-9

Bohnes, F. A., Gregg, J. S., \& Laurent, A. (2017). Environmental Impacts of Future Urban Deployment of Electric Vehicles: Assessment Framework and Case Study of Copenhagen for 2016-2030. Environmental Science ${ }^{3}$ Technology, 51 (23), 13995-14005. doi: 10.1021/acs.est.7b01780

Brown, D. G., Page, S. E., Riolo, R., \& Rand, W. (2004). Agent-based and analytical modeling to evaluate the effectiveness of greenbelts. Environmental Modelling $\&$ Software, 19 (12), 1097-1109. doi: 10.1016/j.envsoft.2003.11.012

Brunner, S. H., Huber, R., \& Gret-Regamey, A. (2017). Mapping uncertainties in the future provision of ecosystem services in a mountain region in Switzerland.Regional Environmental Change, 17 (8), 2309-2321. doi: $10.1007 /$ s10113-017-1118-4

Bryan, B. A., Nolan, M., McKellar, L., Connor, J. D., Newth, D., Harwood, T., . . . Hatfield-Dodds, S. (2016). Land-use and sustainability under intersecting global change and domestic policy scenarios: Trajectories for Australia to 2050. Global Environmental Change-Human and Policy Dimensions, 38 , 130152. doi: $10.1016 /$ j.gloenvcha.2016.03.002

Daniel, C. J., Frid, L., Sleeter, B. M., \& Fortin, M. J. (2016). State-and-transition simulation models: a framework for forecasting landscape change. Methods in Ecology and Evolution, 7 (11), 1413-1423. doi: 10.1111/2041-210x.12597

Duan, Y. Q., Li, X., Zhang, L. P., Liu, W., Liu, S. A., Chen, D., \& Ji, H. Y. (2020). Detecting spatiotemporal changes of large-scale aquaculture ponds regions over 1988-2018 in Jiangsu Province, China using Google Earth Engine.Ocean \& Coastal Management, 188 . doi: 10514410.1016/j.ocecoaman.2020.105144

Eitelberg, D. A., van Vliet, J., Doelrnan, J. C., Stehfest, E., \& Verburg, P. H. (2016). Demand for biodiversity protection and carbon storage as drivers of global land change scenarios. Global Environmental ChangeHuman and Policy Dimensions, 40 , 101-111. doi: 10.1016/j.gloenvcha.2016.06.014 
Fan, J., Wang, Q., Wang, Y. F., Chen, D., \& Zhou, K. (2018). Assessment of coastal development policy based on simulating a sustainable land-use scenario for Liaoning Coastal Zone in China. Land Degradation E Development, 29 (8), 2390-2402. doi: 10.1002/ldr.3013

Fan, J., Wang, Y. F., Wang, C. S., Chen, T., Jin, F. J., Zhang, W. Z., . . . Guo, R. (2019). Reshaping the Sustainable Geographical Pattern: A Major Function Zoning Model and Its Applications in China. Earths Future, 7 (1), 25-42. doi: 10.1029/2018ef001077

Fischer, J., \& Lindenmayer, D. B. (2006). Beyond fragmentation: the continuum model for fauna research and conservation in human-modified landscapes. Oikos, 112 (2), 473-480. doi: 10.1111/j.00301299.2006.14148.x

Gerard, F., Petit, S., Smith, G., Thomson, A., Brown, N., Manchester, S., . . . Feranec, J. (2010). Land cover change in Europe between 1950 and 2000 determined employing aerial photography. Progress in Physical Geography, 34 (2), 183-205. doi: 10.1177/0309133309360141

Goldstein, J. H., Caldarone, G., Duarte, T. K., Ennaanay, D., Hannahs, N., Mendoza, G., . . . Daily, G. C. (2012). Integrating ecosystem-service tradeoffs into land-use decisions. Proceedings of the National Academy of Sciences of the United States of America, 109 (19), 7565-7570. doi: 10.1073/pnas.1201040109

Islam, M. R., Miah, M. G., \& Inoue, Y. (2016). ANALYSIS OF LAND USE AND LAND COVER CHANGES IN THE COASTAL AREA OF BANGLADESH USING LANDSAT IMAGERY. Land Degradation $\& 3$ Development, 27 (4), 899-909. doi: 10.1002/ldr.2339

Krasa, J., Dostal, T., Vrana, K., \& Plocek, J. (2010). PREDICTING SPATIAL PATTERNS OF SEDIMENT DELIVERY AND IMPACTS OF LAND-USE SCENARIOS ON SEDIMENT TRANSPORT IN CZECH CATCHMENTS.Land Degradation \& Development, 21 (4), 367-375. doi: 10.1002/ldr.959

Li, C., Zheng, H., Li, S. Z., Chen, X. S., Li, J., Zeng, W. H., . . . Daily, G. C. (2015). Impacts of conservation and human development policy across stakeholders and scales. Proceedings of the National Academy of Sciences of the United States of America, 112 (24), 7396-7401. doi: 10.1073/pnas.1406486112

Ma, Z. J., Melville, D. S., Liu, J. G., Chen, Y., Yang, H. Y., Ren, W. W., . . . Li, B. (2014). ECOSYSTEMS MANAGEMENT Rethinking China's new great wall. Science, 346 (6212), 912-914. doi: 10.1126/science. 1257258

Matthews, R. B., Gilbert, N. G., Roach, A., Polhill, J. G., \& Gotts, N. M. (2007). Agent-based land-use models: a review of applications. Landscape Ecology, 22 (10), 1447-1459. doi: 10.1007/s10980-007-9135-1

Najmuddin, O., Deng, X. Z., \& Jia, S. Q. (2017). Scenario analysis of land use change in Kabul River Basin - A river basin with rapid socio-economic changes in Afghanistan.Physics and Chemistry of the Earth, 101 , 121-136. doi: 10.1016/j.pce.2017.06.002

Ottinger, M., Clauss, K., \& Kuenzer, C. (2016). Aquaculture: Relevance, distribution, impacts and spatial assessments - A review. Ocean \& Coastal Management, 119 , 244-266. doi: 10.1016/j.ocecoaman.2015.10.015

Parcerisas, L., Marull, J., Pino, J., Tello, E., Coll, F., \& Basnou, C. (2012). Land use changes, landscape ecology and their socioeconomic driving forces in the Spanish Mediterranean coast (El Maresme County, 1850-2005). Environmental Science \& Policy, 23 , 120-132. doi: 10.1016/j.envsci.2012.08.002

Prestele, R., Arneth, A., Bondeau, A., de Noblet-Ducoudre, N., Pugh, T. A. M., Sitch, S., . . . Verburg, P. H. (2017). Current challenges of implementing anthropogenic land-use and land-cover change in models contributing to climate change assessments. Earth System Dynamics, 8 (2), 369-386. doi: 10.5194/esd-8-3692017

Schwartz, N. B., Uriarte, M., Gutierrez-Velez, V. H., Baethgen, W., DeFries, R., Fernandes, K., \& PinedoVasquez, M. A. (2015). Climate, landowner residency, and land cover predict local scale fire activity in 
the Western Amazon.Global Environmental Change-Human and Policy Dimensions, 31 , 144-153. doi: 10.1016/j.gloenvcha.2015.01.009

Wang, X. X., Xiao, X. M., Zou, Z. H., Chen, B. Q., Ma, J., Dong, J. W., . . . Li, B. (2020). Tracking annual changes of coastal tidal flats in China during 1986-2016 through analyses of Landsat images with Google Earth Engine. Remote Sensing of Environment, 238 . doi: 11098710.1016/j.rse.2018.11.030

Wang, Y. F., \& Fan, J. (2020). Multi-scale analysis of the spatial structure of China's major function zoning. Journal of Geographical Sciences, 30 (2), 197-211. doi: 10.1007/s11442-020-1723-x

Yi, L., Qian, J., Kobuliev, M., Han, P. P., \& Li, J. (2020). Dynamic Evaluation of the Impact of Human Interference during Rapid Urbanisation of Coastal Zones: A Case Study of Shenzhen. Sustainability, 12 (6). doi: $225410.3390 / \mathrm{su} 12062254$

Zhang, C., Zhong, S., Wang, X., Shen, L., Liu, L. T., \& Liu, Y. J. (2019). Land Use Change in Coastal Cities during the Rapid Urbanization Period from 1990 to 2016: A Case Study in Ningbo City, China. Sustainability, 11 (7). doi: 212210.3390/su11072122

Table 1 the principles for the land use reclassification

\begin{tabular}{lll}
\hline Classification of the source data & Value & Reclassification \\
\hline No Data & 0 & No Data \\
Cropland, rainfed & 10 & Cropland \\
Cropland, irrigated or post-flooding & 20 & \\
Mosaic cropland $(>50 \%) /$ natural vegetation(tree, shrub, herbaceous cover $)(<50 \%)$ & 30 & \\
Mosaic natural vegetation (tree, shrub, herbaceous cover) $(>50 \%) /$ cropland $(<50 \%)$ & 40 & \\
Tree cover, broadleaved, evergreen, closed to open $(>15 \%)$ & 50 & Tree cover \\
Tree cover, broadleaved, deciduous, closed to open $(>15 \%)$ & 60 & \\
Tree cover, needleleaved, evergreen, closed to open $(>15 \%)$ & 70 & \\
Tree cover, needleleaved, deciduous, closed to open $(>15 \%)$ & 80 & \\
Tree cover, mixed leaf type (broadleaved and needleleaved) & 90 & \\
Mosaic tree and shrub (>50\%)/ herbaceous cover $(<50 \%)$ & 100 & \\
Mosaic herbaceous cover $(>50 \%) /$ tree and shrub $(<50 \%)$ & 110 & Shrubland \\
Shrubland & 120 & \\
Grassland & 130 & Grassland \\
Lichens and mosses & 140 & \\
Sparse vegetation (tree, shrub, herbaceous cover $)(<15 \%)$ & 150 & \\
Tree cover, flooded, fresh or brakish water & 160 & Swamp \\
Tree cover, flooded, saline water & 170 & \\
Shrub or herbaceous cover, flooded, fresh/ saline/ brakish water & 180 & \\
Urban areas & 190 & Urban area \\
Bare areas & 200 & Bareland \\
Water bodies & 210 & Water bodies \\
Permanent snow and ice & 220 & Permanent snow and ice \\
\hline
\end{tabular}

Table 2 the actual and simulated land use values in 2018

\begin{tabular}{lllll}
\hline Classification & The actual values(\%) & The simulated values(\%) & Relative errors(\%) & Accuracy(\%) \\
\hline cropland & 48.5692 & 48.6233 & -0.1114 & 99.8886 \\
treecover & 37.7966 & 37.7452 & 0.1359 & 99.8641 \\
shrubland & 0.8440 & 0.8648 & -2.4595 & 97.5405 \\
grassland & 8.2254 & 8.2250 & 0.0045 & 99.9955
\end{tabular}




\begin{tabular}{lllll}
\hline Classification & The actual values(\%) & The simulated values(\%) & Relative errors(\%) & Accuracy(\%) \\
\hline swamp & 0.4536 & 0.4547 & -0.2291 & 99.7709 \\
urban & 2.0873 & 2.0640 & 1.1134 & 98.8866 \\
bareland & 0.0260 & 0.0260 & 0.0194 & 99.9806 \\
water & 1.9426 & 1.9417 & 0.0470 & 99.9530 \\
snow & 0.0552 & 0.0552 & 0.0000 & 100.0000 \\
\hline
\end{tabular}

Table 3 the Probability matrix in the primitive development scenario

\begin{tabular}{llllllllll}
\hline Class & $\begin{array}{l}\text { Cropland } \\
(\%)\end{array}$ & $\begin{array}{l}\text { Treecover } \\
(\%)\end{array}$ & $\begin{array}{l}\text { Shrubland } \\
(\%)\end{array}$ & $\begin{array}{l}\text { Grassland } \\
(\%)\end{array}$ & $\begin{array}{l}\text { Swamp } \\
(\%)\end{array}$ & Urban $(\%)$ & $\begin{array}{l}\text { Bareland } \\
(\%)\end{array}$ & Water $(\%)$ & Sn \\
\hline cropland & 99.85 & 0.08 & 0.00 & 0.00 & 0.00 & 0.05 & 0.00 & 0.02 & 0.0 \\
treecover & 0.59 & 99.37 & 0.02 & 0.01 & 0.00 & 0.00 & 0.00 & 0.00 & 0.0 \\
shrubland & 0.97 & 2.24 & 96.73 & 0.02 & 0.00 & 0.01 & 0.00 & 0.02 & 0.0 \\
grassland & 0.05 & 0.73 & 0.00 & 99.12 & 0.00 & 0.08 & 0.00 & 0.01 & 0.0 \\
swamp & 0.00 & 0.01 & 0.00 & 0.00 & 99.93 & 0.05 & 0.00 & 0.01 & 0.0 .000 \\
urban & 0.00 & 0.00 & 0.00 & 0.00 & 0.00 & 100.00 & 0.00 & 0.00 & 0.0 \\
bareland & 0.00 & 0.00 & 0.00 & 0.00 & 0.00 & 0.08 & 99.79 & 0.13 & 0.0 \\
water & 0.37 & 0.03 & 0.00 & 0.03 & 0.11 & 0.03 & 0.00 & 99.42 & 0.00 \\
snow & 0.00 & 0.00 & 0.00 & 0.00 & 0.00 & 0.00 & 0.00 & 0.00 & 10 \\
\hline
\end{tabular}

Table 4 the probability matrix in the rapid urban expansion scenario

\begin{tabular}{llllllllll}
\hline Class & $\begin{array}{l}\text { Cropland } \\
(\%)\end{array}$ & $\begin{array}{l}\text { Treecover } \\
(\%)\end{array}$ & $\begin{array}{l}\text { Shrubland } \\
(\%)\end{array}$ & $\begin{array}{l}\text { Grassland } \\
(\%)\end{array}$ & $\begin{array}{l}\text { Swamp } \\
(\%)\end{array}$ & Urban $(\%)$ & $\begin{array}{l}\text { Bareland } \\
(\%)\end{array}$ & Water $(\%)$ & Sn \\
\hline cropland & 99.57 & 0.22 & 0.00 & 0.01 & 0.00 & 0.20 & 0.00 & 0.01 & 0.0 \\
treecover & 0.62 & 99.33 & 0.03 & 0.01 & 0.00 & 0.00 & 0.00 & 0.00 & 0.0 \\
shrubland & 3.02 & 8.56 & 88.32 & 0.01 & 0.02 & 0.07 & 0.00 & 0.00 & 0.0 \\
grassland & 0.38 & 0.11 & 0.00 & 99.37 & 0.00 & 0.13 & 0.00 & 0.01 & 0.0 \\
swamp & 0.01 & 0.02 & 0.00 & 0.00 & 99.85 & 0.10 & 0.00 & 0.01 & 0.0 .0 \\
urban & 0.00 & 0.00 & 0.00 & 0.00 & 0.00 & 100.00 & 0.00 & 0.00 & 0.0 \\
bareland & 0.01 & 0.00 & 0.00 & 1.63 & 0.00 & 0.05 & 98.30 & 0.00 & 0.0 \\
water & 0.45 & 0.01 & 0.00 & 0.25 & 0.46 & 0.03 & 0.03 & 98.75 & 0.0 \\
snow & 0.00 & 0.00 & 0.00 & 0.00 & 0.00 & 0.00 & 0.00 & 0.00 & 10 \\
\hline
\end{tabular}

Table5 the probability matrix of the land use in 2008-2014

\begin{tabular}{llllllllll}
\hline Class & $\begin{array}{l}\text { Cropland } \\
(\%)\end{array}$ & $\begin{array}{l}\text { Treecover } \\
(\%)\end{array}$ & $\begin{array}{l}\text { Shrubland } \\
(\%)\end{array}$ & $\begin{array}{l}\text { Grassland } \\
(\%)\end{array}$ & $\begin{array}{l}\text { Swamp } \\
(\%)\end{array}$ & Urban $(\%)$ & $\begin{array}{l}\text { Bareland } \\
(\%)\end{array}$ & Water $(\%)$ & Sn \\
\hline cropland & 99.52 & 0.06 & 0.00 & 0.01 & 0.00 & 0.40 & 0.00 & 0.01 & 0.0 \\
treecover & 0.32 & 99.65 & 0.01 & 0.01 & 0.00 & 0.00 & 0.00 & 0.00 & 0.0 \\
shrubland & 0.14 & 2.99 & 96.82 & 0.00 & 0.01 & 0.03 & 0.00 & 0.00 & 0.0 \\
grassland & 0.07 & 0.02 & 0.00 & 99.66 & 0.00 & 0.23 & 0.00 & 0.01 & 0.0 \\
swamp & 0.06 & 0.02 & 0.00 & 0.01 & 99.36 & 0.18 & 0.00 & 0.37 & 0.0 \\
urban & 0.00 & 0.00 & 0.00 & 0.00 & 0.00 & 100.00 & 0.00 & 0.00 & 0.00 .0 \\
bareland & 0.08 & 0.00 & 0.00 & 0.00 & 0.00 & 0.37 & 99.42 & 0.14 & 0.0
\end{tabular}




\begin{tabular}{llllllllll}
\hline Class & $\begin{array}{l}\text { Cropland } \\
(\%)\end{array}$ & $\begin{array}{l}\text { Treecover } \\
(\%)\end{array}$ & $\begin{array}{l}\text { Shrubland } \\
(\%)\end{array}$ & $\begin{array}{l}\text { Grassland } \\
(\%)\end{array}$ & $\begin{array}{l}\text { Swamp } \\
(\%)\end{array}$ & Urban $(\%)$ & $\begin{array}{l}\text { Bareland } \\
(\%)\end{array}$ & Water $(\%)$ & Sn \\
\hline water & 0.10 & 0.01 & 0.00 & 0.23 & 0.17 & 0.07 & 0.01 & 99.42 & 0.0 \\
snow & 0.00 & 0.00 & 0.00 & 0.00 & 0.00 & 0.00 & 0.00 & 0.00 & 10 \\
\hline
\end{tabular}

Table6 the probability matrix of the land use change in 2014-2018

\begin{tabular}{llllllllll}
\hline Class & $\begin{array}{l}\text { Cropland } \\
(\%)\end{array}$ & $\begin{array}{l}\text { Treecover } \\
(\%)\end{array}$ & $\begin{array}{l}\text { Shrubland } \\
(\%)\end{array}$ & $\begin{array}{l}\text { Grassland } \\
(\%)\end{array}$ & $\begin{array}{l}\text { Swamp } \\
(\%)\end{array}$ & Urban $(\%)$ & $\begin{array}{l}\text { Bareland } \\
(\%)\end{array}$ & Water $(\%)$ & Sn \\
\hline cropland & 99.04 & 0.61 & 0.00 & 0.01 & 0.01 & 0.32 & 0.00 & 0.00 & 0.0 \\
treecover & 0.05 & 99.94 & 0.01 & 0.00 & 0.00 & 0.00 & 0.00 & 0.00 & 0.0 \\
shrubland & 0.07 & 0.96 & 98.92 & 0.00 & 0.01 & 0.03 & 0.00 & 0.00 & 0.0 \\
grassland & 0.01 & 0.18 & 0.00 & 99.68 & 0.01 & 0.12 & 0.01 & 0.00 & 0.0 \\
swamp & 0.01 & 0.03 & 0.00 & 0.00 & 99.37 & 0.41 & 0.00 & 0.19 & 0.0 \\
urban & 0.00 & 0.00 & 0.00 & 0.00 & 0.00 & 100.00 & 0.00 & 0.00 & 0.0 \\
bareland & 0.18 & 0.00 & 0.00 & 0.00 & 0.00 & 0.40 & 99.37 & 0.05 & 0.0 \\
water & 0.00 & 0.00 & 0.00 & 0.01 & 0.04 & 0.01 & 0.00 & 99.94 & 0.00 \\
snow & 0.00 & 0.00 & 0.00 & 0.00 & 0.00 & 0.00 & 0.00 & 0.00 & 10 \\
\hline
\end{tabular}

Table7 the land use proportion from 2020 to 2030 in the scenario1

\begin{tabular}{llllllllll}
\hline Year & $\begin{array}{l}\text { Cropland } \\
(\%)\end{array}$ & $\begin{array}{l}\text { Treecover } \\
(\%)\end{array}$ & $\begin{array}{l}\text { Shrubland } \\
(\%)\end{array}$ & $\begin{array}{l}\text { Grassland } \\
(\%)\end{array}$ & $\begin{array}{l}\text { Swamp } \\
(\%)\end{array}$ & Urban $(\%)$ & $\begin{array}{l}\text { Bareland } \\
(\%)\end{array}$ & Water $(\%)$ & Sn \\
\hline 2020 & 48.74 & 37.68 & 0.83 & 8.16 & 0.46 & 2.12 & 0.03 & 1.94 & 0.0 \\
2022 & 48.90 & 37.56 & 0.81 & 8.09 & 0.46 & 2.15 & 0.03 & 1.95 & 0.0 \\
2024 & 49.07 & 37.44 & 0.79 & 8.03 & 0.46 & 2.18 & 0.03 & 1.95 & 0.0 \\
2026 & 49.23 & 37.33 & 0.77 & 7.96 & 0.46 & 2.21 & 0.03 & 1.95 & 0.0 \\
2028 & 49.40 & 37.21 & 0.76 & 7.90 & 0.46 & 2.24 & 0.03 & 1.95 & 0.0 \\
2030 & 49.56 & 37.09 & 0.74 & 7.83 & 0.47 & 2.27 & 0.03 & 1.95 & 0.0 \\
\hline
\end{tabular}

Table 8 the land use proportion from 2020 to 2030 in the scenario 2

\begin{tabular}{llllllllll}
\hline Year & $\begin{array}{l}\text { Cropland } \\
(\%)\end{array}$ & $\begin{array}{l}\text { Treecover } \\
(\%)\end{array}$ & $\begin{array}{l}\text { Shrubland } \\
(\%)\end{array}$ & $\begin{array}{l}\text { Grassland } \\
(\%)\end{array}$ & $\begin{array}{l}\text { Swamp } \\
(\%)\end{array}$ & Urban $(\%)$ & $\begin{array}{l}\text { Bareland } \\
(\%)\end{array}$ & Water $(\%)$ & Sn \\
\hline 2020 & 48.66 & 37.73 & 0.76 & 8.19 & 0.46 & 2.19 & 0.03 & 1.92 & 0.0 \\
2022 & 48.75 & 37.66 & 0.68 & 8.15 & 0.48 & 2.30 & 0.03 & 1.90 & 0.0 \\
2024 & 48.83 & 37.58 & 0.61 & 8.11 & 0.49 & 2.41 & 0.03 & 1.88 & 0.0 \\
2026 & 48.91 & 37.50 & 0.55 & 8.07 & 0.50 & 2.52 & 0.03 & 1.86 & 0.0 \\
2028 & 48.99 & 37.41 & 0.50 & 8.03 & 0.51 & 2.62 & 0.03 & 1.85 & 0.0 \\
2030 & 49.07 & 37.32 & 0.45 & 8.00 & 0.52 & 2.73 & 0.03 & 1.83 & 0.0 \\
\hline
\end{tabular}

Table9 the land use proportion from 2020 to 2030 in the scenario3 


\begin{tabular}{llllllllll}
\hline Year & $\begin{array}{l}\text { Cropland } \\
(\%)\end{array}$ & $\begin{array}{l}\text { Treecover } \\
(\%)\end{array}$ & $\begin{array}{l}\text { Shrubland } \\
(\%)\end{array}$ & $\begin{array}{l}\text { Grassland } \\
(\%)\end{array}$ & $\begin{array}{l}\text { Swamp } \\
(\%)\end{array}$ & Urban $(\%)$ & $\begin{array}{l}\text { Bareland } \\
(\%)\end{array}$ & Water $(\%)$ & Sn \\
\hline 2020 & 48.47 & 37.72 & 0.82 & 8.21 & 0.46 & 2.30 & 0.03 & 1.94 & 0.0 \\
2022 & 48.36 & 37.64 & 0.80 & 8.19 & 0.46 & 2.52 & 0.03 & 1.94 & 0.0 \\
2024 & 48.26 & 37.56 & 0.78 & 8.18 & 0.47 & 2.73 & 0.03 & 1.94 & 0.0 \\
2026 & 48.16 & 37.49 & 0.76 & 8.16 & 0.47 & 2.94 & 0.03 & 1.94 & 0.0 \\
2028 & 48.06 & 37.41 & 0.75 & 8.14 & 0.47 & 3.16 & 0.03 & 1.94 & 0.0 \\
2030 & 47.95 & 37.33 & 0.73 & 8.13 & 0.48 & 3.37 & 0.03 & 1.93 & 0.0 \\
\hline
\end{tabular}

Table 10 the land use proportion from 2020 to 2030 in the scenario4

\begin{tabular}{llllllllll}
\hline Year & $\begin{array}{l}\text { Cropland } \\
(\%)\end{array}$ & $\begin{array}{l}\text { Treecover } \\
(\%)\end{array}$ & $\begin{array}{l}\text { Shrubland } \\
(\%)\end{array}$ & $\begin{array}{l}\text { Grassland } \\
(\%)\end{array}$ & $\begin{array}{l}\text { Swamp } \\
(\%)\end{array}$ & Urban $(\%)$ & $\begin{array}{l}\text { Bareland } \\
(\%)\end{array}$ & Water $(\%)$ & Sn \\
\hline 2020 & 48.12 & 38.09 & 0.84 & 8.21 & 0.46 & 2.26 & 0.03 & 1.94 & 0.0 .0 \\
2022 & 47.68 & 38.39 & 0.84 & 8.19 & 0.46 & 2.42 & 0.03 & 1.95 & 0.0 \\
2024 & 47.24 & 38.68 & 0.83 & 8.17 & 0.46 & 2.59 & 0.03 & 1.95 & 0.0 \\
2026 & 46.81 & 38.96 & 0.83 & 8.15 & 0.46 & 2.75 & 0.03 & 1.95 & 0.0 .0 \\
2028 & 46.38 & 39.25 & 0.83 & 8.13 & 0.46 & 2.91 & 0.03 & 1.95 & 0.0 \\
2030 & 45.96 & 39.53 & 0.82 & 8.11 & 0.46 & 3.07 & 0.03 & 1.96 & 0.0 \\
\hline
\end{tabular}

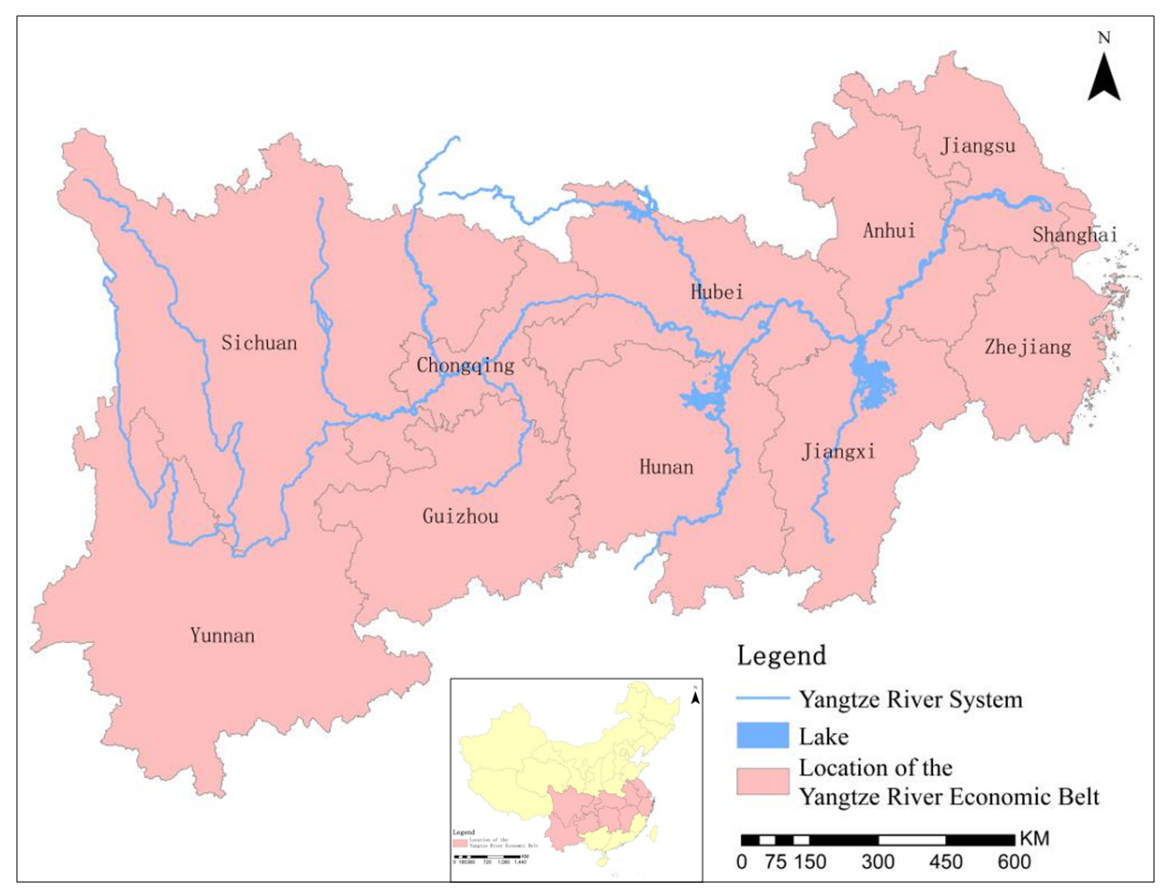

